\title{
Proposta de um modelo de gestão integrada da cadeia de suprimentos: aplicação no segmento de eletrodomésticos
}

\author{
Reinaldo Fagundes dos Santos ${ }^{\mathrm{a} *}$, João Murta Alves ${ }^{\mathrm{b}}$ \\ a*reinaldof@cis-erp.com.br, ITA, Brasil \\ bmurta@ita.br, ITA, Brasil
}

\begin{abstract}
Resumo
0 espectro da competitividade entre as organizações manufatureiras, numa economia cada vez mais globalizada, já não se limita ao jogo de forças entre as organizações concorrentes, mas acontece de fato entre cadeias de suprimentos. Entretanto, os atuais modelos de gestão da cadeia de suprimentos não vêm cumprindo seu papel, havendo grande disparidade entre os potenciais benefícios e a prática. 0 presente trabalho tem como objetivo propor um modelo de SCM e seu método de implementação, visando aumentar a capacidade de resposta ao mercado consumidor das empresas manufatureiras. 0 modelo proposto utiliza os conceitos da Manufatura Enxuta, da Teoria das Restrições e do modelo SCOR em um ambiente de Tecnologia da Informação e Comunicação. São aplicados também os conceitos do Triple Bottom Line na busca da sustentabilidade. A avaliação de sua eficácia é feita através de uma aplicação no segmento de eletrodomésticos, permitindo sugerir a ampliação do escopo de sua utilização.
\end{abstract}

Palavras-chave

Gerenciamento da Cadeia de Suprimentos (SCM). Teoria das Restrições (TOC). Manufatura Enxuta (Lean). Supply Chain Operations Reference (SCOR). Tecnologia da Informação e Comunicação (TIC).

\section{Introdução}

Na atualidade, a economia é fortemente influenciada pela comunicação, em que as empresas de manufatura, e não apenas elas, têm enfrentado um ambiente complexo e de competição acirrada. Para Martins (2011), diante desse cenário de crescentes desafios impostos pelo mercado, a vantagem competitiva de uma empresa passa a estar atrelada ao dinamismo de todos os membros de sua cadeia de suprimentos, logo, uma empresa já não concorre com outra individualmente, a concorrência acontece através de suas cadeias de suprimentos de seus produtos ou de seus concorrentes (Srinivasan et al., 2005).

Como conseguir um resultado sustentável para uma empresa sem uma boa integração de sua cadeia de suprimentos? 0 gerenciamento da cadeia de suprimentos (SCM - Supply Chain Management) vem se apresentando como uma tendência nessa busca, pois é uma filosofia que propõe processos enxutos, eliminação de desperdícios e minimização de estoques (Stéen, 2006). Infelizmente, os modelos de SCM aplicados atualmente não atingem seus objetivos e frequentemente há uma grande disparidade entre a realidade e os potenciais benefícios (Martins, 2011).

Dessa forma, torna-se decisiva para que as organizações manufatureiras prosperem nesse novo cenário a utilização de um sistema que possibilite integrar as empresas participantes da cadeia de suprimentos, repensando as condicionantes que auxiliam as empresas a enfrentarem os desafios do dia a dia de forma eficiente e duradoura. Essa necessidade também se aplica à realidade competitiva das empresas pertencentes ao mercado brasileiro de eletrodomésticos, que se veem na contingência de aprimorar o seu modelo de gestão e integração para suportar seus objetivos estratégicos de crescimento diante da concorrência globalizada. 
A empresa SmallGoods, pseudônimo de uma montadora de grande porte desse segmento e que foi o objeto do estudo aqui descrito, se viu também na necessidade de buscar, através de uma melhor gestão e integração de sua cadeia de suprimentos, vantagens competitivas perante seus concorrente.

0 presente trabalho tem como objetivo propor um modelo de SCM e seu método de implantação visando aumentar a integração entre as organizações de uma cadeia de suprimentos. 0 objetivo também inclui a preocupação com a sustentabilidade para o que, em sintonia com o movimento Triple Bottom Line (3BL), busca-se o equilíbrio entre o resultado das empresas, o bem-estar das pessoas e a preservação do meio ambiente. 0 modelo proposto utiliza os conceitos da Manufatura Enxuta (Lean Manufacturing), da Teoria das Restrições (TOC - Theory of Constraints), e do modelo SCOR (Supply Chain Operations Reference), suportados por um ambiente de Tecnologia da Informação e Comunicação (TIC).

Este trabalho foi estruturado em seções: a proposta metodológica é apresentada na próxima seção, seguida do referencial teórico, em que é feita uma análise sobre o estado da arte dos modelos de SCM, da Manufatura Enxuta, da TOC, dos conceitos básicos da TIC. Na seção seguinte é apresentada a estrutura do mercado de pequenos eletrodomésticos no Brasil. A seguir é proposto um modelo de gestão integrada da cadeia de suprimentos, seguido da sua aplicação no mercado apresentado. Finalmente, a última seção apresenta as conclusões deste trabalho a partir da análise dos resultados obtidos na aplicação do modelo proposto, destacando a contribuição deste trabalho e sugerindo pesquisas para a continuidade do aprimoramento de sistemas de SCM.

\section{Proposta metodológica}

Para atender os objetivos deste trabalho, a metodologia de pesquisa utilizada, ilustrada na Figura 1, foi estruturada sobre quatro pilares: quanto à sua natureza, abordagem, objetivos e procedimentos técnicos utilizados. A importância da escolha adequada da metodologia de pesquisa a ser utilizada justifica-se pela necessidade de embasamento científico adequado, buscando a melhor abordagem de forma a endereçar as questões da pesquisa, pois a ciência é constituída da aplicação de técnicas, seguindo um método e apoiando-se em fundamentos epistemológicos (Miguel, 2007).

Como apresentado na Figura 1, optou-se por um trabalho de natureza aplicada, buscando solucionar um problema real que surgiu recentemente nas organizações industriais. Devido ao cunho das necessidades do trabalho, a abordagem deverá ser qualitativa e com a interação entre o pesquisador e

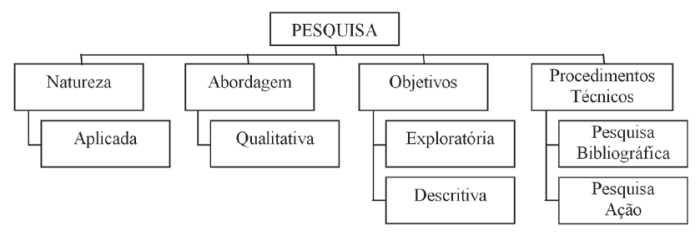

Figura 1. Proposta metodológica. Fonte: adaptado de Santos (2010).

seu objeto de pesquisa. Quanto ao objetivo, adotou-se o tipo descritivo e exploratório, utilizado quando o nível de exploração se baseia em uma teoria em ascensão (Miguel et al., 2010).

Para os procedimentos técnicos, optou-se inicialmente por uma pesquisa bibliográfica, visitas a empresas do setor estudado, seguida de pesquisa ação.

Nesta pesquisa, ao mesmo tempo em que foram feitos o diagnóstico e a análise das empresas estudadas, foram propostas mudanças que buscaram o aprimoramento das práticas analisadas, caracterizando o procedimento técnico pesquisa ação.

\section{Gestão da Cadeia de Suprimentos (SCM)}

0 ambiente vivenciado atualmente pelas empresas exige a integração de toda cadeia de suprimentos através do seu gerenciamento, que abrange todo o fluxo de transformação do produto (Santos \& Forcellini, 2012). Sellitto \& Mendes (2006) complementam afirmando que a SCM não deve apenas focar processos logísticos, mas sim todos os processos de negócios relacionados aos requisitos dos clientes finais. Assim, a SCM pode ser considerada um importante modelo para alcançar vantagens competitivas, tendo como objetivo adicionar valor na visão dos clientes e demais stakeholders (Melo \& Alcântara, 2011).

Neste trabalho, a cadeia de suprimentos acontece a partir de um segmento, produto ou empresa e se ramifica desde o consumidor final até a matéria-prima básica, porém seu gerenciamento ocorre somente a partir de uma empresa denominada "Empresa focal", representada na Figura 2.

\subsection{Gestão dos processos na cadeia de suprimentos}

Nos anos 1980 e 1990, as organizações manufatureiras concentraram esforços na mudança de gestão departamental para a gestão por processos. No final da década de 1990 surgiu um novo paradigma segundo o qual os processos de negócios tornaram-se os processos da cadeia de suprimentos e não mais somente os da organização. 
A mudança da gestão individual para o gerenciamento das relações entre os membros da SCM visa a integração dos processos de negócios na cadeia de suprimentos, criando um sistema de valor (Santos \& Forcellini, 2012). Diante dessa necessidade de integração, Martins (2011) enaltece o modelo de Cooper et al. (1998), que apresenta três elementos: os processos de negócios, o gerenciamento dos componentes e a estrutura da cadeia de suprimentos. Lambert (2010) afirma que os oito macroprocessos de negócios, apresentados na Figura 3, correspondem a um longo processo de desenvolvimento do próprio autor, iniciado em 1992. Desses processos, a gestão do relacionamento com o cliente e a gestão da demanda têm sido consideradas como o cerne para uma gestão eficiente da cadeia de suprimentos.

\subsection{Gestão do relacionamento com os clientes}

Para Ballou (2006), a dependência entre organizações reflete a diferença de poder entre elas,

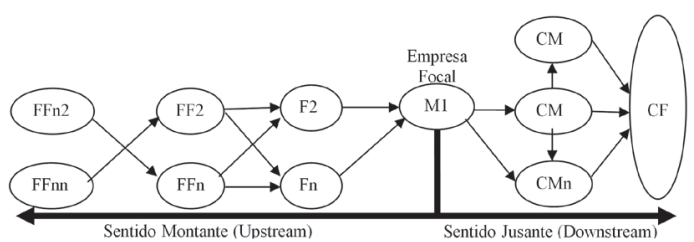

Figura 2. Cadeia de suprimentos da Empresa focal. Fonte: adaptado de Santos (2010). pois uma organização tem mais ou menos poder, em relação às outras, à medida que controla os recursos necessários às outras ou reduz sua própria dependência, por meio do controle desses recursos. 0 poder exercido na cadeia de suprimentos sofre mutações ao longo do tempo: na década passada, boa parte do poder passou dos fabricantes para os varejistas, em função do exercício de preferência do consumidor.

As indústrias são afetadas por diversos riscos de desabastecimento e interrupção que podem incorrer de várias formas e serem influenciados por diversos fatores. Esses fatores variam desde uma instabilidade geopolítica em uma região fornecedora até fatores mais localizados, como as greves nos fornecedores, no entanto, o risco de desabastecimento está normalmente relacionado ao poder exercido na cadeia e, consequentemente, ao processo de gestão de relacionamento.

\subsection{Gestão da demanda na cadeia de suprimentos}

A gestão da demanda consiste em criar um fluxo coordenado da demanda entre os membros da cadeia de suprimentos e o cliente final, tendo como objetivo equilibrar a oferta em relação à demanda e calcular os estoques de segurança necessários para o nível de serviço predefinido (Pereira et al., 2010). A eficiência na gestão da demanda é afetada diretamente pelo

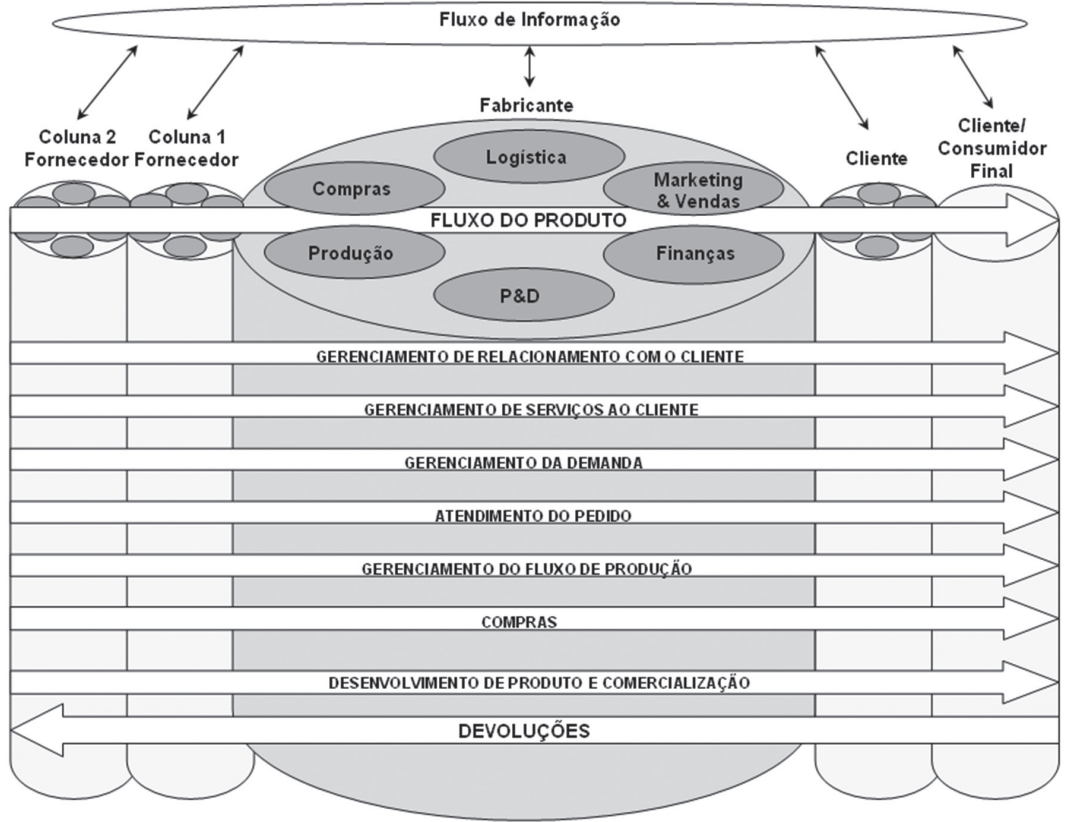

Figura 3. SCM: Integrando e gerenciando os processos de negócios através da cadeia de suprimentos. Fonte: adaptado de Cooper et al. (1998). 
fluxo de informações, em que eventuais interferências podem acarretar uma redução do nível de serviço, associada à queda do giro de estoque (Melo \& Alcântara, 2011).

0 fluxo de informações é um dos componentes que influenciam a gestão da demanda. A variabilidade dos estoques na SC, normalmente decorrente dos problemas de comunicação, é um fenômeno conhecido como efeito chicote, que corresponde às distorções entre a demanda real e a prevista, que se propagam à montante da cadeia de suprimentos, devido ao incremento de "segurança" no nível de estoque (Pereira et al., 2010). Esse efeito resulta em variação da demanda, dificultando a gestão de estoques e o gerenciamento e planejamento dos pedidos de compra ao longo da cadeia, impactando negativamente nos custos das organizações (Fioriolli \& Fogliatto, 2009).

Coelho, Follmann \& Rodriguez (2009) resumem o efeito chicote como o efeito gerado da expectativa de demanda que não se observa na prática, o que resulta na amplificação da demanda no sentido inverso ao sentido do consumo, conforme ilustrado na Figura 4.

0 efeito chicote não é um fenômeno novo na cadeia de suprimentos, uma vez que o contexto da ampliação da demanda foi descoberto nos EUA por Forrester, em 1958, e posteriormente estudado por Burbidge, em 1961 (Coelho et al., 2009; Pereira et al., 2010).

\subsection{Gestão do estoque na cadeia de suprimentos}

O objetivo do gerenciamento de estoques é assegurar que o produto esteja disponível no tempo e nas quantidades desejadas. Uma das principais preocupações de uma organização manufatureira na atualidade é a redução do inventário. Diante desse cenário, o efeito chicote passa a ser um ponto importante a ser estudado, pois resulta diretamente em oscilação dos níveis de estoques, que tendem a se intensificar ao se afastar do ponto de consumo da cadeia (Coelho et al., 2009). Para a minimização dos estoques sem a redução do nível de serviço ao consumidor, as empresas varejistas vêm utilizando o sistema de estoque gerenciado pelo fornecedor (VMI - Vendor Management lnventory).

\subsection{Sustentabilidade na cadeia de suprimentos}

Segundo Lages et al. (2010), o termo desenvolvimento sustentável nasceu durante a Comissão Mundial sobre o Meio Ambiente e Desenvolvimento, criada pela ONU em dezembro de 1983, e a publicação do relatório final - conhecido como Relatório de Brundtland - em 1987. Define-se desenvolvimento sustentável como um modelo econômico, político, social, cultural e ambiental equilibrado, que satisfaça as necessidades das gerações atuais sem comprometer a capacidade das gerações futuras de satisfazerem suas próprias necessidades (Catalisa, 2010).

Nas empresas manufatureiras, após o reconhecimento da qualidade como gerador de vantagens competitivas, foram criados sistemas de gestão para atender a outras questões importantes, como o meio ambiente (Pereira \& Cruz, 2007). A atuação mais integrada das cadeias de suprimentos pode favorecer a gestão ambiental e proporcionar oportunidades importantes para o desenvolvimento de negócios alinhado com a sustentabilidade (Pedroso \& Swicker, 2007).

\subsection{Triple Bottom Line - 3BL}

Para Oliveira et al. (2012), um negócio deve ser avaliado não somente com relação aos resultados financeiros, mas também diante do seu impacto sobre a economia como um todo, de sua consciência ambiental e de sua responsabilidade social, que correspondem aos três pilares do 3BL. Kleindorfer et al. (2005) destacam que um dos sintomas da atual pressão pela sustentabilidade é o movimento 3BL relativo à relação entre o lucro, as pessoas e o planeta atuando na cultura, estratégia e operação das empresas.

Para Lages et al. (2010), as iniciativas do Triple Bottom Line devem estar alinhadas com as diretrizes estratégicas das organizações para garantir uma implementação eficaz nas três dimensões básicas da

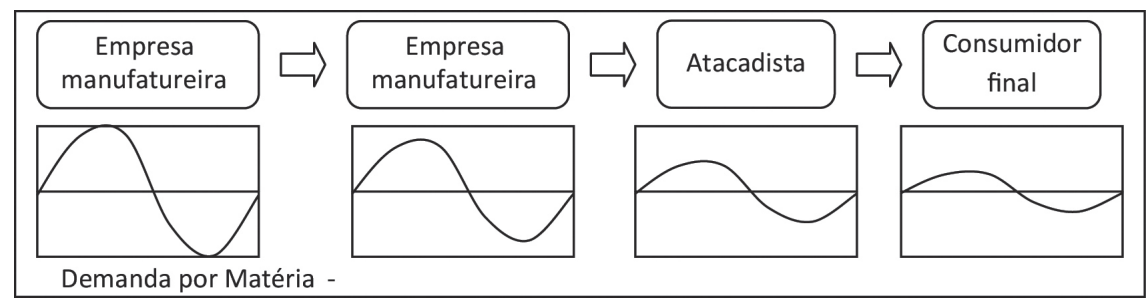

Figura 4. Amplificação da demanda ou efeito chicote. Fonte: adaptado de Taylor (2005). 
sustentabilidade: econômica, ambiental e social. As organizações que adotarem o conceito e as práticas do Triple Bottom Line tendem a ter uma gestão mais consciente e uma maior clareza quanto à própria missão (Lages et al., 2010).

A Figura 5 ilustra a iteração dos stakeholders com a relação entre as três dimensões para a sustentabilidade (3BL).

\subsection{Indicadores e normas associadas à sustentabilidade}

Pereira \& Cruz (2007) afirmam que a responsabilidade ambiental e social da sustentabilidade está associada com a iteração de três normas, IS014001, OHSAS18001 e SA8000. Uma empresa sustentável deve preocupar-se com o meio ambiente, através da certificação 1S014001, associada a uma preocupação com a segurança ocupacional, obtida através da certificação OHSAS18001, além de preocupar-se com a responsabilidade social, que pode ser comprovada pela certificação SA8000. A utilização da certificação segundo os requisitos de cada uma dessas normas pode favorecer a geração de um indicador de sustentabilidade para as organizações.

\subsection{O modelo de referência SCOR}

0 modelo de referência SCOR (Supply Chain Operations Reference), foi desenvolvido pelo Supply
Chain Council (SCC) com a assistência das 70 maiores empresas de manufatura do mundo e está em contínuo desenvolvimento desde o lançamento da versão 1.0 até a atual, em vigor no ano de 2010, a versão 9.0. Ele pode ser descrito como o modelo mais promissor de tomada de decisões estratégicas na cadeia de suprimentos (Hudson, 2004).

O SCOR proporciona em um único modelo a conexão de processos de negócios, métricas, melhores práticas e características tecnológicas, de forma a proporcionar suporte à comunicação entre os participantes da cadeia de suprimentos e melhorar efetivamente o seu gerenciamento (Scor 9.0, 2009).

Pires (2009) interpreta o SCOR como sendo um modelo composto por cinco processos de negócios básicos: planejar, abastecer, produzir, entregar e retornar. O SCOR é um modelo que também provê diretrizes padronizadas, sendo indicado para a configuração e medição de desempenho das cadeias de suprimentos.

\section{Manufatura enxuta/Pensamento enxuto}

A produção enxuta ajuda a produzir com qualidade, de maneira diversificada e com baixo nível de estoques diante das flutuações da demanda do mercado, consolidando uma maneira otimizada de organizar e gerenciar os relacionamentos, tanto com os clientes quanto com os demais membros da cadeia de fornecedores (Walter \& Zvirtes, 2008).

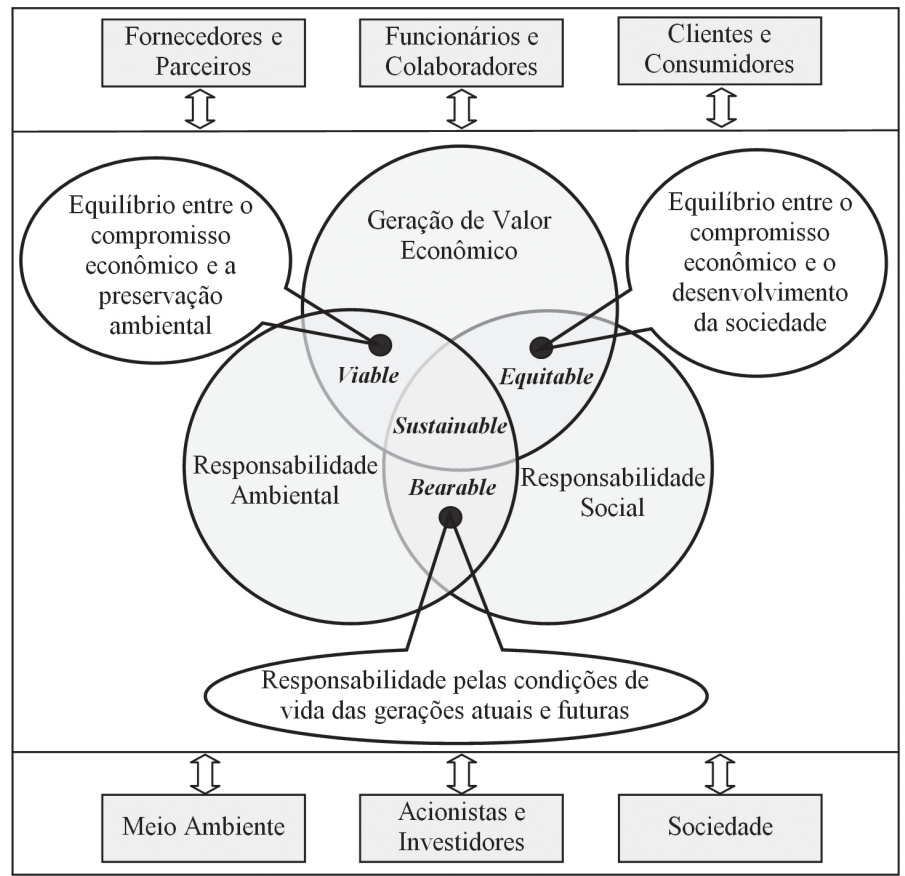

Figura 5. llustração do 3BL (Triple Bottom line). Fonte: adaptado de Pedroso \& Swicker (2007) e Lages et al. (2010). 
Dentre os desafios para implantação dos princípios e práticas lean, o maior deles se refere ao dilema de não se permitir o excesso de inventário mantendo um nivel excelente de serviço ao cliente. A eliminação dessa perda (o excesso de estoques) é considerada um grande desafio, pois a minimização dos estoques não depende somente de uma boa gestão interna, e sim de um sincronismo entre a empresa, seus clientes e fornecedores.

A concepção do pensamento enxuto se norteia em cinco princípios, enunciados por Womack \& Jones (2004): valor, a cadeia de valor, fluxo, produção puxada e perfeição.

\subsection{O fluxo de valor}

A definição de valor e seu respectivo fluxo correspondem ao ponto de partida da mentalidade enxuta. A definição: o conjunto de ações necessárias para deslocar um produto por todos os seus fluxos de transformação, desde a matéria-prima até o cliente final (Greef \& Freitas, 2012).

\subsection{Mapeamento do fluxo de valor (estado atual e estado futuro)}

Para Walter \& Zvirtes (2008), o objetivo a ser alcançado ao se mapear o fluxo de valor atual é identificar as atividades que não agregam valor e as fontes de desperdício nos processos produtivos, eliminando-as através da implantação de um fluxo de valor em um estado futuro. Dessa forma, com o mapeamento do estado atual concluído, inicia-se o desenho do mapa do estado futuro, ou seja, com as melhorias esperadas nos processos atuais. De vital importância é a preparação conjunta de um plano de ações para tornar realidade o mapa de estado futuro.

\subsection{O mapeamento do fluxo de valor estendido à cadeia de suprimentos}

Um fluxo de valor estendido é uma adaptação da tradicional prática enxuta aplicada à cadeia de suprimentos. Para Hirschheimer (2009), a aplicação da produção puxada em uma cadeia de suprimentos não se diferencia substancialmente da aplicação nos processos de uma empresa, exceto pelo fato de o fluxo de valor estar associado a toda ação necessária para levar um produto desde a matéria-prima até os braços dos consumidores, ou seja, constitui um circuito fechado entre a demanda e o suprimento.

\section{Teoria das restrições (TOC - Theory of Constraints)}

Inconformado com as deficiências gerenciais na tomada de decisão motivadas pelos paradigmas existentes até a década de 1970, Eliyahu Goldratt desenvolveu um novo sistema de gestão denominado teoria das restrições (TOC - Theory of Constraints). $\mathrm{Na}$ tentativa de quebrar os paradigmas utilizados até então, Goldratt desenvolveu, dentro da TOC, a contabilidade de ganhos que quebra um dos maiores paradigmas da gestão financeira e contábil das organizações: a substituição do custeio pela análise do ganho de cada produto.

Pergher et al. (2011) consideram que a teoria das restrições é formada por um conjunto de indicadores, divididos entre as classes locais e globais, com o objetivo comum de gerenciar globalmente a organização na direção da meta da empresa. Para Santos et al. (2010), a teoria das restrições, também conhecida como manufatura síncrona ou tamborpulmão-corda, é fundamentalmente um processo de melhoramento contínuo baseado em uma metodologia composta de cinco etapas em que a gestão das restrições leva a empresa a uma visão sistêmica global. Os cinco passos da TOC são:

1. Identificar a(s) restrição(ões) do sistema;

2. Explorar a(s) restrição(ões) do sistema;

3. Subordinar tudo mais às decisões tomadas na etapa dois;

4. Elevar a(s) restrição(ões) do sistema;

5. Se, em um dos passos anteriores, uma restrição for quebrada, voltar para a etapa um. Mas não permita que a inércia se torne uma restrição no sistema.

\subsection{Programação de produção: tambor, pulmão e corda (TPC)}

0 método tambor-pulmão-corda corresponde ao princípio básico da TOC voltado para a programação da produção, com o objetivo de otimizar o sistema de produção de acordo com a capacidade de cada recurso (Souza, 2005). A aplicação do método pode ser melhor compreendida segundo o entendimento das três palavras que o compõem.

- Tambor - com a mesma analogia dos tambores que definem a cadência das marchas militares, na TPC o recurso restritivo é o tambor, ou seja, o ponto que deve ditar a cadência de todo o sistema produtivo.

- Pulmão - o pulmão é a representação da proteção do Recurso com Restrição de Capacidade (RRC) contra possíveis incertezas que podem pôr em risco a chegada dos materiais para o cumprimento da sequência de trabalho que o RRC vai executar. 
- Corda - representa a sincronização entre a necessidade de chegada de materiais no estoque protetor (pulmão) e a admissão de matérias-primas no sistema, garantindo assim um sistema com o mínimo de estoques intermediários e sempre com a programação de produção puxada.

\subsection{Extensão do tambor, pulmão e corda para a cadeia de suprimentos}

0 uso do TPC abrange muitos outros desafios quando estendido para a gestão da cadeia de suprimentos. Uma vez que o ganho de toda a cadeia é controlado pelo recurso restritivo localizado em uma das empresas da cadeia de suprimentos, os programas mestres de produção de cada empresa deveriam ser submetidos à capacidade limitada daquele recurso restritivo. Esse programa mestre será o tambor da $\mathrm{SC}$, determinando o ritmo de produção de todas as companhias da cadeia.

A Figura 6, proposta por Srinivasan, Srinivasan e Choi (2005), busca resolver a dificuldade de subordinar centenas de empresas a um elo restritivo. Esse modelo foi denominado TCP simplificado (TPC-S), que difere do TPC normal (apresentado na primeira parte da Figura 6) pelo planejamento dos recursos internos, que busca eliminar qualquer gargalo interno nas empresas e, dessa forma, a restrição passará a ser o mercado, eliminando-se assim o pulmão de proteção do RRC.

\section{Tecnologia da Informação e Comunicação - TIC}

A Tecnologia da Informação (Tl) esteve presente nas transformações ocorridas nas indústrias nas últimas décadas através dos sistemas de gerenciamento empresariais, inicialmente voltados para os processos internos das empresas e mais recentemente também voltados para toda a sua cadeia de suprimento. Diante de um cenário complexo e de competição acirrada, que exige um ambiente de mudanças constantes, as empresas de manufatura têm frequentemente adotado soluções de comunicação na área de Tecnologia da Informação (Low et al., 2011).

\subsection{VMI e o uso de ferramentas da TIC na gestão da demanda e estoques}

Com a evolução da TIC foi possível o desenvolvimento dos processos de gestão e não foi diferente com o Vendor Management Inventory, que corresponde a um modelo de gestão integrada de estoques. Disney \& Towill (2003) afirmam que o VMI não é uma estratégia recente, uma vez que ele vem sendo discutido desde 1958.

Segundo Perales et al. (2008), os Programas de Reposição Automática (PRA) são um conjunto de técnicas que têm como objetivo suportar o relacionamento integrado entre o fornecedor e o cliente, que incluem: Quick Response (QR), Continuous Replenishment (CR), Efficient Consumer Response (ECR), Collaborative Planning, Forecasting and Replenishment (CPFR) que, na essência, são sempre uma aplicação do VMI.

\subsection{B2B (Business to Business)}

Para Bandeira \& Maçada (2008), o B2B seria a forma popular de representar a expressão business to business e se refere à realização de negócios e

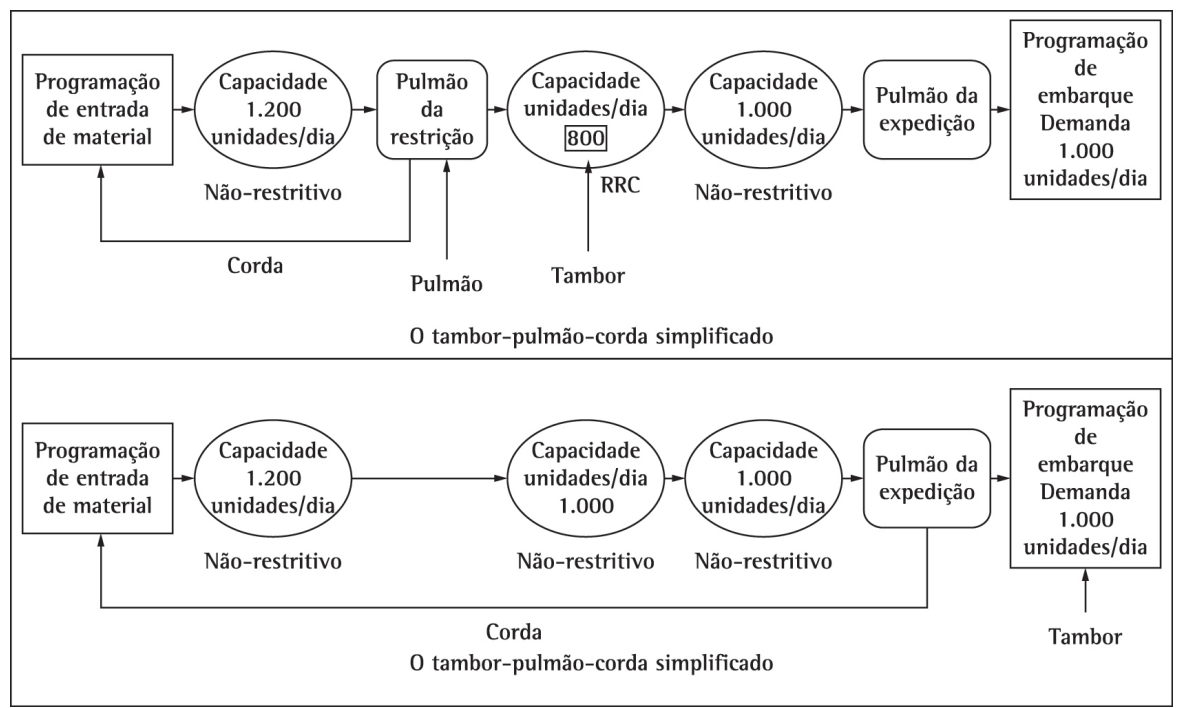

Figura 6. Comparação entre os modelos TPC e TPC-S. Fonte: adaptado de Srinivasan et al. (2005). 
transações entre duas empresas através do mercado eletrônico, alterando assim o modo de operação nas SCs.

A internet habilitou a troca de informações comerciais entre as empresas, vinculando almoxarifados e garantindo um melhor nível de informação em toda a SC. Com a internet de alta velocidade tornou-se possível a comunicação em tempo real dos dados entre as empresas que disponibilizam, em portais, sistemas de troca de informações referentes aos negócios em andamento entre as partes envolvidas.

\subsection{Evolução da TIC e os sistemas de gestão}

Segundo Santos (2010), no início nos anos 1960 apareceram as listas de materiais mecanizadas, denominadas BOM (Bill of Materials), na década de 1970, a evolução da informática propiciou o surgimento do planejamento da necessidade de materiais (Material Requirements Planning - MRP), nos anos 1980, o MRP evoluiu para o planejamento dos recursos da manufatura e foi denominado MRPII (Manufacturing Resource Planning). Esse modelo foi sobreposto, nos anos 1990, pelo ERP (Enterprise Resources Planning), que passou a planejar todos os recursos da empresa e não somente a manufatura.

Neste novo século, com a evolução da comunicação de alta velocidade, está surgindo um novo sistema para sobrepor-se ao ERP, um modelo de planejamento e programação vançados (APS - Advanced Planning and Scheduling).

\subsection{Planejamento de recursos empresariais - ERP}

Para Oliveira \& Silveira (2010), um ERP tem a finalidade de integrar todas as informações e funções de uma empresa por meio de uma ferramenta computacional única, com capacidade para controlar e suportar as necessidades dos departamentos em tempo real. A integração requer maior capacidade de processamento e maior complexidade, levando a necessidade de tecnologia mais avançada de informação e comunicação, disponíveis somente na década de 1990, quando surgiram os primeiros sistemas ERPs.

0 ERP dedica-se primordialmente à empresa, e no que diz respeito ao gerenciamento da cadeia de suprimentos, limita-se aos parceiros comerciais imediatos, ou seja, a somente um elo da cadeia.

\subsection{Planejamento e programação avançados - APS}

Quando o escopo é ampliado para tratar de questões além das fronteiras da empresa, se faz necessário utilizar outras ferramentas que ajudem na integração da empresa com seus fornecedores e clientes, para o que, na atualidade, vem despontando o sistema APS. 0 grande desafio tem sido a integração entre o ERP e o APS, pois a operação do APS depende dos bancos de dados obtidos através do sistema ERP.

\section{0 modelo proposto e sua operacionalidade}

Em geral os modelos atuais de SCM estão baseados na confiança entre seus membros, o que costumeiramente não é possível em todas as camadas. 0 objetivo dessa seção é apresentar uma proposta de um modelo de SCM que atue de forma integradora, independentemente da necessidade de confiança entre os membros envolvidos.

\subsection{Estruturação do modelo proposto}

Esse modelo foi concebido pela integração entre os conceitos e princípios da teoria das restrições (TOC), os princípios e ferramentas da manufatura enxuta (lean), as ferramentas da tecnologia da informação e comunicação (TIC) e o modelo de referência SCOR.

A Figura 7 ilustra a estrutura básica do modelo proposto, que tem por objetivo o aumento da capacidade de resposta das empresas da cadeia ao mercado consumidor, proporcionando produtos de melhor qualidade, a preço justo e com entregas mais rápidas.

A base do modelo é a reconfiguração da SC com base no modelo SCOR associado a contratos de parceria de longo prazo. É fundamental que os contratos apresentem uma clara definição de controles, para que todos os membros possam promover, de forma segura, investimentos em produtos, gestão e processos. Essa base sustenta os objetivos do modelo através de quatro pilares: a Teoria das Restrições, o Pensamento Enxuto, a Tecnologia da Informação e Comunicação e o modelo de referência SCOR.

\subsubsection{TOC}

Com a visão sistêmica que lhe é intrínseca, apoiará na identificação das restrições além de disponibilizar o seu método de melhoria contínua. A ferramenta TPCS buscará a subordinação dos membros da cadeia à demanda do mercado, além da identificação de possiveis restrições e dessa forma contribuirá para a 
minimização dos riscos de falta de suprimentos e na identificação das prioridades nas parcerias e contratos de fornecimento.

\subsubsection{LEAN}

Disponibilizará a cultura e as ferramentas para a identificação e eliminação dos desperdícios em todos os players da cadeia de suprimentos. Uma das ferramentas a ser utilizada é o Mapeamento do Fluxo de Valor aplicado a SC (MFV estendido), disseminando a cultura da busca da perfeição. A integração dos conceitos da TOC com os princípios e ferramentas lean promoverá a minimização dos estoques. 0 Kaisen, para eliminação de desperdícios, utiliza a padronização associada à disciplina como suporte para evitar retrocessos das conquistas.

\subsubsection{SCOR}

0 modelo SCOR servirá de base na reconfiguração da SC para atingir-se o mapa do estado futuro do fluxo de valor, referenciando a estrutura e documentando os processos de negócios, além de associar as métricas, as melhores práticas e as características tecnológicas. Portanto, o modelo SCOR proporcionará a derivação para o estado futuro, comparando e quantificando o desempenho de cada empresa em relação a outras da mesma categoria para estabelecer objetivos baseados no resultado best in class. Outra função é a de proporcionar uniformidade à comunicação entre os participantes da cadeia de suprimentos e melhorar efetivamente o seu gerenciamento, evitando que as empresas identifiquem e nomeiem seus próprios processos, porém, esses processos podem ser comunicados e relacionados na cadeia.

\subsection{4. $T I C$}

A TIC terá papel fundamental na integração sistêmica das empresas participantes da cadeia de suprimentos. 0 uso da tecnologia de informação e comunicação passa a ser, neste trabalho, um forte capacitador para o processo de integração, melhorando o fluxo de informações e materiais, pois capturar e dividir informações em tempo real tem sido essencial para aumentar o desempenho da cadeia de suprimentos. Com a atual complexidade do mercado e em um ambiente globalizado, passa a ser de grande importância o uso de ferramentas de informação, comunicação e sincronização de alta velocidade.

\subsection{Operacionalidade do modelo proposto}

Segundo Santos (2010), quando todos os participantes de uma SC estão integrados e atuam como uma entidade única, havendo a conciliação entre fornecimento e demanda por todos os elos, o resultando deverá ser a melhora do desempenho. A Figura 8 ilustra a proposta de integração entre os pilares do modelo proposto na busca dos objetivos, que em um ambiente de TIC atuam de forma sincronizada nas empresas da cadeia.

\subsection{Interação entre a TOC, Lean e cadeia de suprimentos}

As diferenças entre as culturas da TOC, que têm foco sistêmico, e Lean, que têm foco no processo, podem ser resolvidas de forma às duas abordagens se complementarem. A TOC, com objetivo primário de restrição, pode identificar os processos chave que provêm uma maior alavancagem relativa à perspectiva global. Subsequentemente, a cultura e as ferramentas oferecidas pelo pensamento enxuto, com objetivo primário de simplificação, podem remover as atividades que não agregam valor. 0 resultado é a redução dos lead-times, correspondendo a uma redução nos estoques através das cadeia de suprimentos.

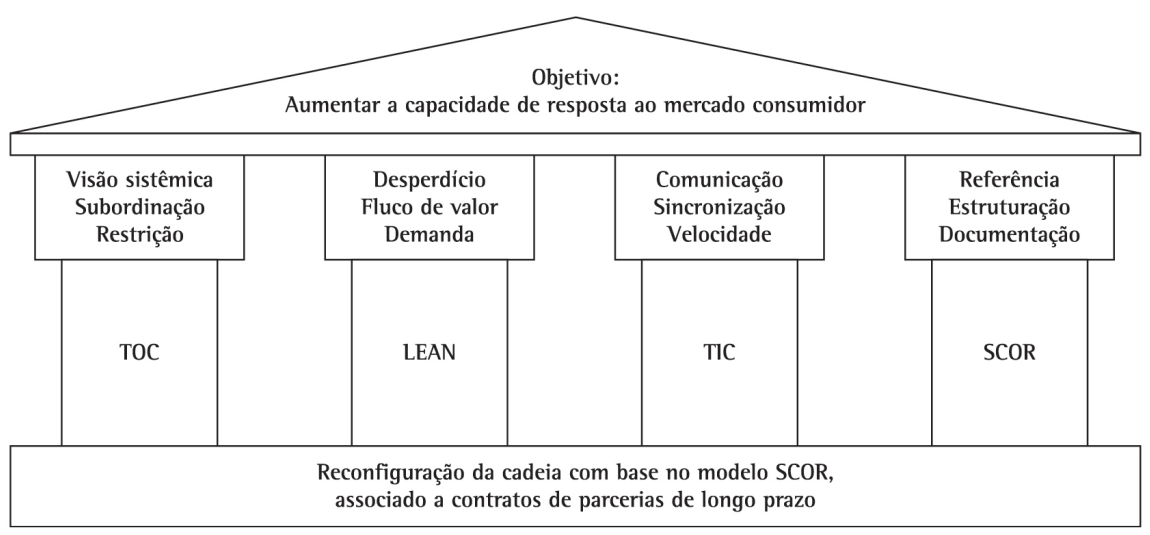

Figura 7. Estrutura do modelo proposto. Fonte: adaptado de Santos (2010). 


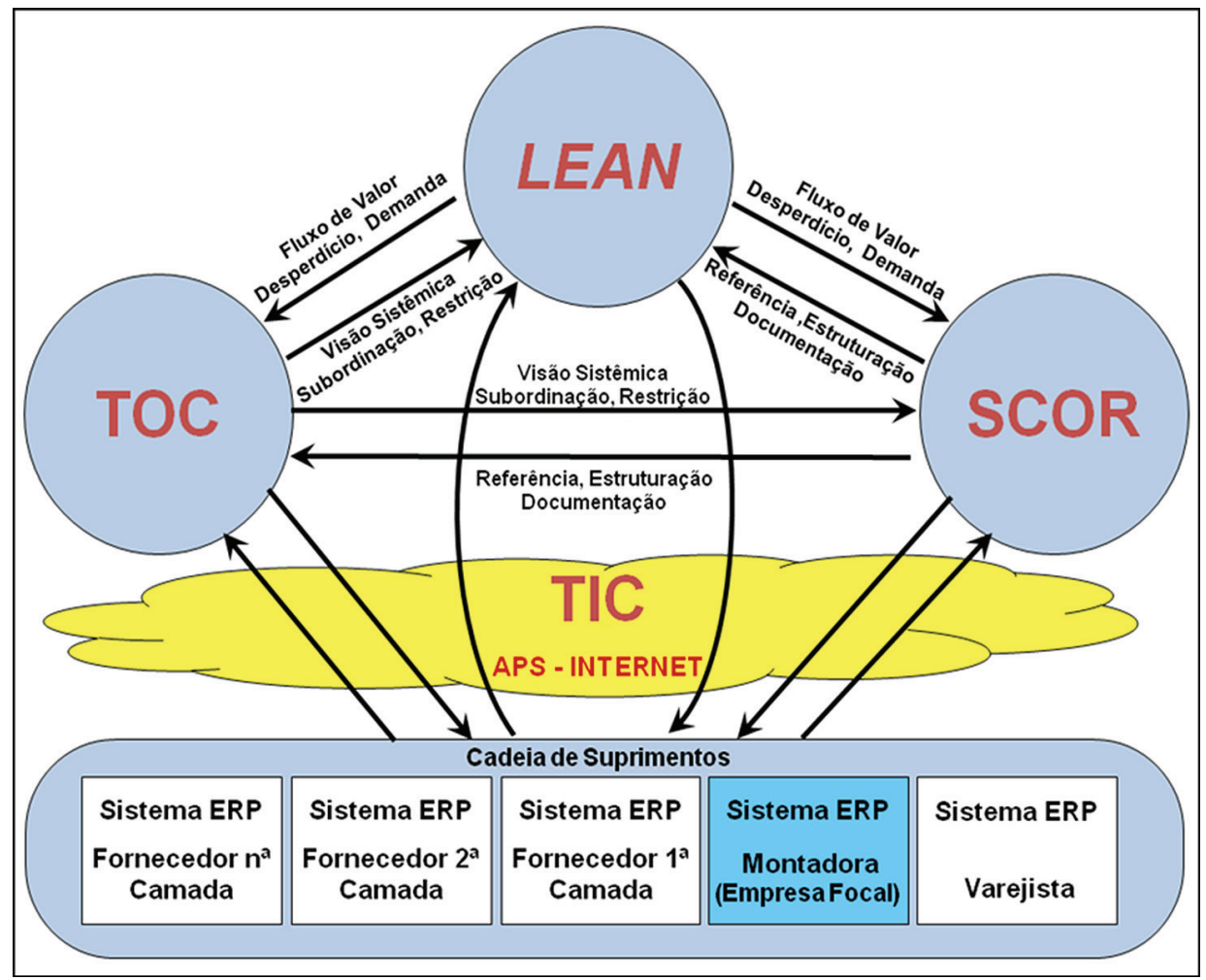

Figura 8. Integração dos subsistemas do modelo proposto. Fonte: adaptado de Santos (2010).

\subsection{Interação entre o SCOR, Lean e cadeia de suprimentos}

O modelo SCOR proporciona em um único modelo a conexão de processos de negócios, métricas, melhores práticas e características tecnológicas de forma a proporcionar suporte à comunicação entre os participantes da cadeia de suprimentos, melhorando efetivamente o seu gerenciamento. Porém sua eficiência está ligada no conhecimento detalhado da estrutura da SC, papel designado ao Lean, através do MFV estendido.

\subsection{Interação entre a TOC, SCOR e cadeia de suprimentos}

Na derivação para o estado futuro, proporcionada pelo SCOR, a aplicação da TOC no modelo representa a quebra de paradigmas, gerando uma visão sistêmica da organização com foco no resultado global e não local. Nessa interação, a função da TOC é identificar possíveis restrições que estão impedindo a cadeia de suprimentos de atingir seus resultados. Ao serem quebradas as restrições internas do sistema, a restrição passará a ser a demanda e, dessa forma, pode-se utilizar a ferramenta TPC-S.

\subsection{Suporte da TIC no processo de integração}

A TIC terá papel fundamental como facilitador na operação dos outros pilares durante a integração sistêmica das empresas participantes da cadeia de suprimentos, capturando e dividindo informações em tempo real de forma a aumentar o desempenho do modelo.

Com a internet de alta velocidade é possível a implementação de sistemas de comunicação eletrônica em diversas camadas da cadeia de suprimentos. Uma B2B promoverá a troca de informações de demanda entre as empresas, vinculando os diversos ERPs e garantindo um melhor nível de integração em toda a SC. Na internet, portais promoverão, de forma segura e em tempo real, a comunicação entre as organizações envolvidas.

Os ERPs dos integrantes da SC se integram com a empresa focal através da captura dos dados disponibilizados pelo APS. Na empresa focal, através do APS, haverá a substituição do modelo de planejamento MRPIl pelo TPC-S. 0 APS sincronizará, além dos fornecedores imediatos, os fornecedores de matériaprima básica, que serão informados, também pelo 
portal, sobre a necessidade de matéria-prima. Dessa forma, a empresa focal poderá subordinar toda a cadeia de suprimentos à sua demanda.

\section{0 mercado de eletrodomésticos}

0 mercado de eletrodomésticos está dividido em três grandes segmentos: pequenos eletrodomésticos, linha branca e linha marrom.

\subsection{O estudo da cadeia de suprimentos escolhida}

0 estudo foi feito em quatro camadas, iniciando em um fabricante (montadora) de produtos, como empresa focal, e mais três camadas à montante. No que se refere à jusante, foram feitos estudos somente com os dados fornecidos pela empresa focal. A empresa SmallGoods, nome fantasia de uma montadora de grande porte, foi a escolhida como empresa focal.

\subsection{Estruturação da pesquisa}

A pesquisa foi fundamentada em visitas às unidades fabris e entrevistas aos funcionários das empresas estudadas. A base estrutural das entrevistas foi a escolha correta dos entrevistados e a geração de um questionário utilizado como guia para deixar as entrevistas mais produtivas.

\subsection{As entrevistas e os questionários}

Os questionários, utilizados como roteiro das entrevistas, foram estruturados conforme os processos do SCOR.

\subsection{Características específicas dessa cadeia}

São sete os principais fabricantes nacionais do segmento escolhido, sendo que fabricam juntos mais de 20 milhões de produtos por ano. Na Figura 9 é possivel observar a estrutura dessa cadeia de suprimentos.

\subsection{Cultura e relações contratuais predominantes}

Em um ambiente com poucos players, existe uma cultura de rivalidade muito bem definida. De forma geral, todas as montadoras de produtos finais são empresas de grande porte, administradas através de ERP.

Com produtos de baixo valor agregado, não é possivel trabalhar com fornecedores e desenvolvimento de produtos exclusivos e nesse segmento não existe a cultura de formalização de contratos de fornecimento de longo prazo. As empresas desse segmento trabalham com fornecimento não garantido a longo e médio prazos, sendo que as cadeias se volatizam à medida que surgem dificuldades no fornecimento, qualidade ou preço.

\subsection{Estrutura da cadeia de suprimentos}

A Figura 10 ilustra a cadeia de suprimentos da SmallGoods, que conta com 3.200 clientes no total, porém $70 \%$ de suas vendas estão concentradas em apenas 50 clientes, dos quais 20 respondem por quase $50 \%$ das vendas da organização.

À montante de sua cadeia são 165 fornecedores diretos dos quais foi escolhida a empresa ElectroGoods para a aplicação do modelo. Continuando à montante,

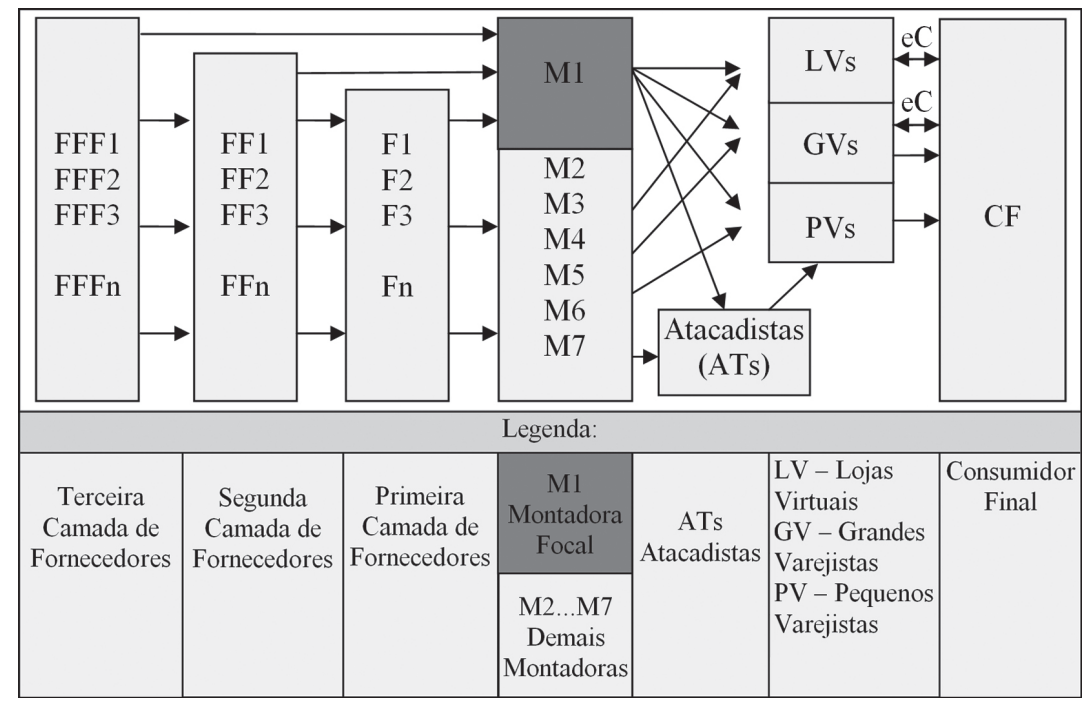

Figura 9. Cadeia de suprimentos do mercado de pequenos eletrodomésticos. Fonte: Santos (2010). 


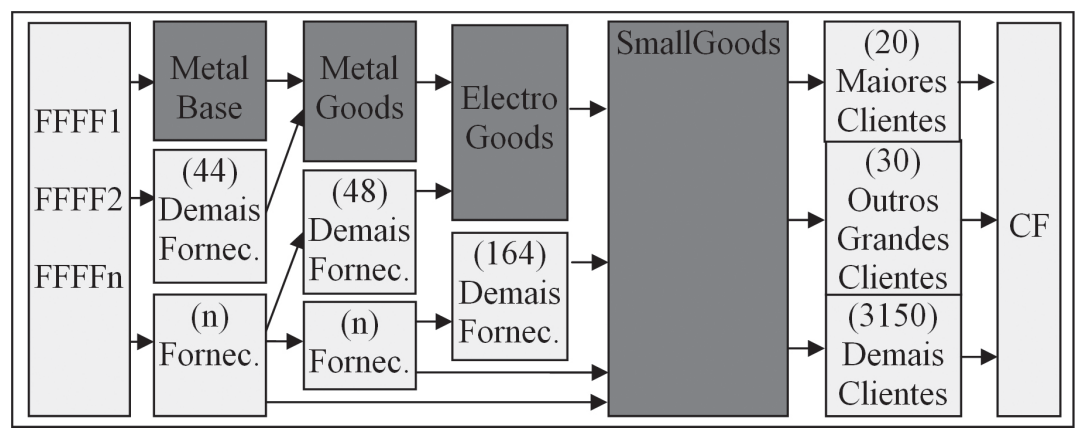

Figura 10. Cadeia de suprimentos da montadora SmallGoods (M1). Fonte: adaptado de Santos (2010).

dos 49 fornecedores da empresa ElectroGoods foi escolhido seu fornecedor estratégico, a MetalGoods. $\mathrm{Na}$ terceira camada de fornecimento, dentre os 45 fornecedores da MetalGoods, foi escolhida a empresa MetalBase como membro estratégico da cadeia estudada. Dessa forma foram estudados o comportamento em três camadas à montante da montadora de eletrodomésticos SmallGoods.

\subsection{Características dessa cadeia de suprimentos}

- Não foi utilizado nenhum modelo de referência no projeto da cadeia;

- Não houve um projeto planejado da cadeia de suprimentos, sendo que a sua estruturação ocorreu de forma natural através dos relacionamentos par a par (fornecedor-cliente) das empresas participantes;

- 0 relacionamento entre os parceiros comerciais é informal, isento de contratos de longo prazo, baseado apenas em previsões de abastecimento e pedidos firmes para curto prazo;

- Ausência do suporte da TIC na integração dos membros da SC;

- A utilização de processos lean ficou restrita à gestão interna das empresas participantes, não se estendendo para a gestão da cadeia.

\subsection{Consequências no desempenho das empresas}

- Produção empurrada;

- Geração de estoques;

- Descompasso da demanda real em cada uma das camadas (efeito chicote);

- Insegurança entre os membros pela inexistência de contratos de longo prazo;

- Limitação no investimento nas empresas pela inexistência de contratos de longo prazo;
- Nível de serviço inadequado mesmo com manutenção de altos estoques.

\subsection{Considerações sobre a cadeia de suprimentos da SmallGoods}

A situação ideal seria a empresa focal (nesse caso a SmallGoods) informar todos os fornecedores, em todas as camadas, sobre a real demanda. Essa situação não é tecnologica e politicamente possível no atual ambiente, pois prover uma comunicação entre todos os players da SC representaria algumas centenas de empresas a serem contatadas e gerenciadas. Como melhorar a gestão da cadeia de suprimentos para reduzir custos e aumentar a capacidade de resposta ao mercado consumidor?

\section{Aplicação do modelo proposto}

Para ilustrar a aplicação do modelo proposto foi escolhida a empresa SmallGoods, do segmento de eletrodomésticos, já caracterizada anteriormente, porém, o modelo não se restringe somente a essa empresa ou a esse segmento. Trata-se de um modelo de complexa implementação, pois envolve em sua aplicação diferentes culturas em diversas empresas, não sendo possível estender os testes a outras cadeias e a outros segmentos.

Como apresentado na Tabela 1, a implantação desse modelo está estruturada em 20 passos, divididos em três fases.

Primeira fase: 0 estado atual do fluxo de valor na cadeia de suprimentos

Passo 1-Passo 5

Foram executados os passos de 1 a 5 da cadeia escolhida.

Passo 6: Padronizar símbolos a serem utilizados

A Figura 11 apresenta os símbolos a serem utilizados.

Passo 7: Definir os indicadores de desempenho 
Tabela 1. Interface entre fases e passos com os pilares do modelo proposto.

\begin{tabular}{|c|c|c|c|}
\hline 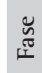 & Passo & ○ \} $&{\text { 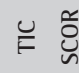 }} \\
{\hline \multirow{12}{*}{1}1} &{\text { 1-Escolher o gerente para o fluxo de valor }} &{ } &{ } \\
{\hline} &{\text { 2-Selecionar uma família de produtos }} &{ } &{ } \\
{\hline} &{\begin{array}{l}\text { 3-Mapear os riscos de abastecimento para a } \\
\text { cadeia de suprimentos da família selecionada }\end{array}} &{ } &{ } \\
{\hline} &{\text { 4-Delimitar um campo de visão gerenciável }} &{ } &{ } \\
{\hline} &{\text { 5-Montar uma equipe }} &{ } &{ } \\
{\hline} &{\text { 6-Padronizar os símbolos a serem utilizados }} &{ } &{ } \\
{\hline} &{\text { 7-Definir os indicadores de desempenho }} &{ } &{ } \\
{\hline} &{\begin{array}{l}\text { 8-Listar as etapas físicas para criar o produto } \\
\text { no estado atual }\end{array}} &{ } &{ } \\
{\hline} &{\begin{array}{l}\text { 9-Desenhar as etapas físicas do mapa do } \\
\text { estado atual }\end{array}} &{ } &{ } \\
{\hline} &{\begin{array}{l}\text { 10-Verificar o 1GS (Indicador Geral de } \\
\text { Sustentabilidade) de cada empresa da cadeia }\end{array}} &{ } &{ } \\
{\hline} &{\begin{array}{l}\text { 11-Listar o fluxo de informaç̧ões para criar o } \\
\text { produto no estado atual }\end{array}} &{ } &{ } \\
{\hline} &{\begin{array}{l}\text { 12-Completar o mapa do estado atual com o } \\
\text { fluxo de informações }\end{array}} &{ } &{ } \\
{\hline \multirow{4}{*}{2}2} &{\begin{array}{l}\text { 13-Projetar a nova cadeia utilizando como } \\
\text { referência o SCOR e buscando transferir a } \\
\text { restrição para a demanda }\end{array}} &{ } &{ } \\
{\hline} &{\begin{array}{l}\text { 14-Dimensionar o pulmão e as cordas } \\
\text { e subordinar os parceiros imediatos e } \\
\text { fornecedores da última camada (contratos de } \\
\text { parceria) }\end{array}} &{ } &{ } \\
{\hline} &{\begin{array}{l}\text { 15-Listar as novas etapas físicas e fluxo de } \\
\text { informações para criar o produto no estado } \\
\text { futuro }\end{array}} &{ } &{ } \\
{\hline} &{\begin{array}{l}\text { 16-Desenhar o mapa do estado futuro do } \\
\text { fluxo de valor }\end{array}} &{ } &{ } \\
{\hline \multirow{4}{*}{3}3} &{\begin{array}{l}\text { 17-Elaborar e implementar contratos de } \\
\text { parceria de longo prazo }\end{array}} &{ } &{ } \\
{\hline} &{\begin{array}{l}\text { 18-Implementar o mapa do estado futuro do } \\
\text { fluxo de valor }\end{array}} &{ } &{ } \\
{\hline} &{\text { 19-Análises dos resultados obtidos }} &{ } &{ } \\
{\hline} &{\begin{array}{l}\text { 20-Voltar ao passo } 1 \text { e não deixar a inércia se } \\
\text { tornar uma restrição no sistema }\end{array}} &{ } &{ } \\
$\hline
\end{tabular}

Para este estudo serão utilizados três indicadores de desempenho: 0 nível de inventário, o nível de serviço ao cliente (OTIF) e o indicador geral de sustentabilidade (IGS).

\section{Passo 8-Passo 12}

Após execução dos passos de 8 a 12, com mais de 100 horas de entrevistas, consulta a documentos e acompanhamento de processos, foi possível estruturar, com detalhes, todas as etapas físicas para criar mil liquidificadores. A Tabela 2 resume essas etapas e a Figura 12 ilustra o estado atual do fluxo de valor da cadeia de suprimentos da SmallGoods.

Segunda fase: 0 estado futuro do fluxo de valor na cadeia de suprimentos

Passo 13: Projetar a nova cadeia utilizando como referência o SCOR e buscando transferir a restrição para a demanda
Nesse passo, a equipe de fluxo de valor iniciou as avaliações para tentar identificar o que deveria ser feito para criar um estado futuro melhor. Foram detalhados os três níveis do SCOR e fixadas as metas para busca de um estado futuro melhor e também foram definidos valores mínimos aceitáveis para os indicadores de sustentabilidade (IGS) e nível de serviços ao cliente (OTIF). Não apareceram gargalos visto que a demanda é de 8 mil produtos por dia e a capacidade de produção das plantas é superior a esse número, portanto a restrição é a demanda, sendo possível a gestão da cadeia através do TPC-S.

Passo 14: Dimensionar o pulmão e as cordas e subordinar os parceiros imediatos e fornecedores de última camada (contratos de parceria)

A equipe de fluxo de valor verificou que parte do resultado negativo do OTIF da SmallGoods era decorrente do mau desempenho de seu fornecedor ElectroGoods e, dessa forma, chegou-se ao consenso de redução dos estoques da SmallGoods e pequeno aumento dos estoques de produtos acabados da ElectroGoods. Com a previsão de assinatura de contratos e subordinação do fornecedor de primeira camada MetalBase foi possível esperar uma redução nos estoques de matéria-prima da MetalGoods sem afetar seu ótimo desempenho quanto ao OTIF.

A empresa SmallGoods decidiu pela aquisição do módulo APS de seu ERP, aumentando assim a possibilidade de sucesso do trabalho, pois a aplicação do TPC-S foi facilitada.

Passo 15: Listar as novas etapas físicas e fluxo de informações para criar o produto no estado futuro

A equipe de fluxo de valor listou as novas etapas físicas e de fluxo de informações de forma a atingir o mapa do estado futuro do fluxo de valor. As etapas físicas foram consolidadas na Tabela 2 .

Passo 16: Desenhar o mapa do estado futuro do fluxo de valor

As ações executadas nos passos 13, 14 e 15 foram incluídas no desenho do mapa do estado futuro, ilustrado na Figura 13. As principais alterações projetadas no estado futuro são:

- Foi aumentado o OTIF da SmallGoods e da ElectroGoods para 95;

- Foram mantidos os IGS das empresas;

- Houve redução nos estoques da SmallGoods e da MetalBase e leve aumento nos estoques da ElectroGoods;

- Inclusão do processo de utilização de embalagens retornáveis da ElectroGoods para a MetalGoods;

- Definição do pulmão de proteção à demanda;

- Subordinação da ElectroGoods, através do TPC-S, com o uso do VMI-B2B; 


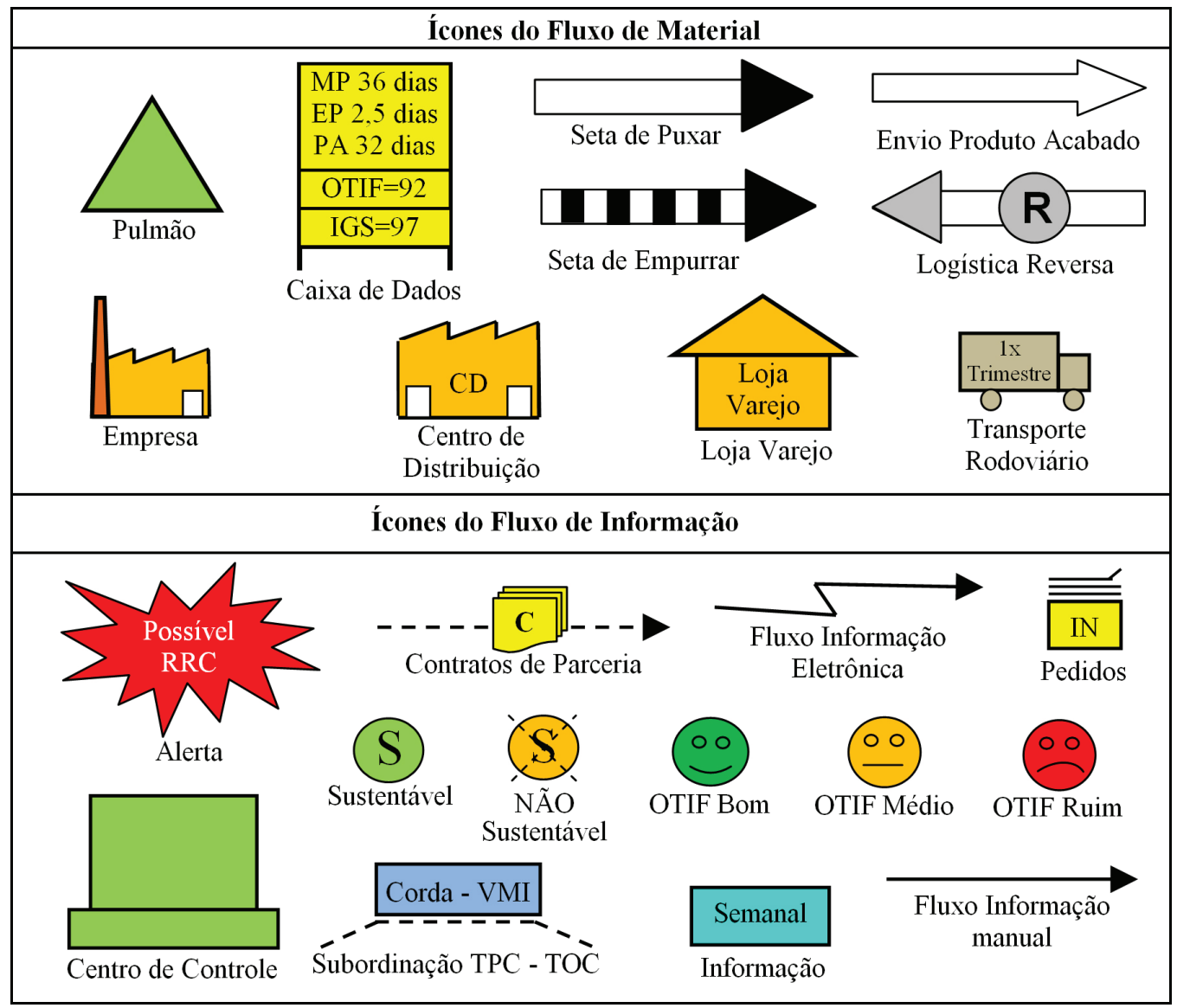

Figura 11. Símbolos padronizados. Fonte: adaptado de Womack \& Jones (2004).

Tabela 2. Resumo das etapas físicas para criar mil liquidificadores.

\begin{tabular}{llcc}
\hline Estado & & Total & $\begin{array}{c}\text { Agregação de } \\
\text { valor }\end{array}$ \\
\hline Atual & Etapas & 62 & 7 \\
& Tempo (minutos) & 458.881 & 495 \\
& Distância total percorrida & \multicolumn{2}{c}{$410 \mathrm{~km}$} \\
Futuro & Etapas & 59 & 8 \\
& Tempo (minutos) & 382.806 & 545 \\
& Distância total percorrida & \multicolumn{2}{c}{$410 \mathrm{~km}$} \\
\hline
\end{tabular}

Tabela 3. Resumo dos resultados obtidos.

\begin{tabular}{lccc}
\hline \multicolumn{1}{c}{ Indicador } & $\begin{array}{c}\text { Estado atual } \\
\text { do fluxo de } \\
\text { valor }\end{array}$ & $\begin{array}{c}\text { Estado futuro } \\
\text { do fluxo de } \\
\text { valor }\end{array}$ & $\begin{array}{c}\text { Resultado } \\
\text { após } \\
\text { implantação } \\
\text { do estado } \\
\text { futuro }\end{array}$ \\
\hline OTIF (médio) & 86,5 & 95 & 91 \\
OTIF (mínimo) & 71 & 90 & 86 \\
Nível estoques (dias) & 318,01 & 265,01 & 293,8 \\
1GS (médio) & 90 & 90 & 90 \\
1GF (mínimo) & 80 & 80 & 80 \\
\hline
\end{tabular}

- Subordinação da MetalBase, através do TPC-S, com o uso do VMl-B2B;

- Proposta de contratos de fornecimento de longo prazo com a MetalBase e a ElectroGoods;

- Opção pelo planejamento da produção (puxado pelo pulmão) através do TPC-S, em substituição ao MRPIl utilizado anteriormente;

- Eliminação dos processos de verificação da qualidade de recebimento para esses itens, tanto na SmallGoods quanto na ElectroGoods.

Terceira fase: 0 processo de melhoramento contínuo

Passo 17: Elaborar e implementar contratos de parceria de longo prazo

Foram elaborados, pela SmallGoods, contratos de fornecimento de longo prazo e apresentados para a ElectroGoods (que já se encontram assinados) e para a MetalBase (ainda em fase de análise e negociação ao final desta tese).

Passo 18: Implementar o mapa do estado futuro do fluxo de valor 


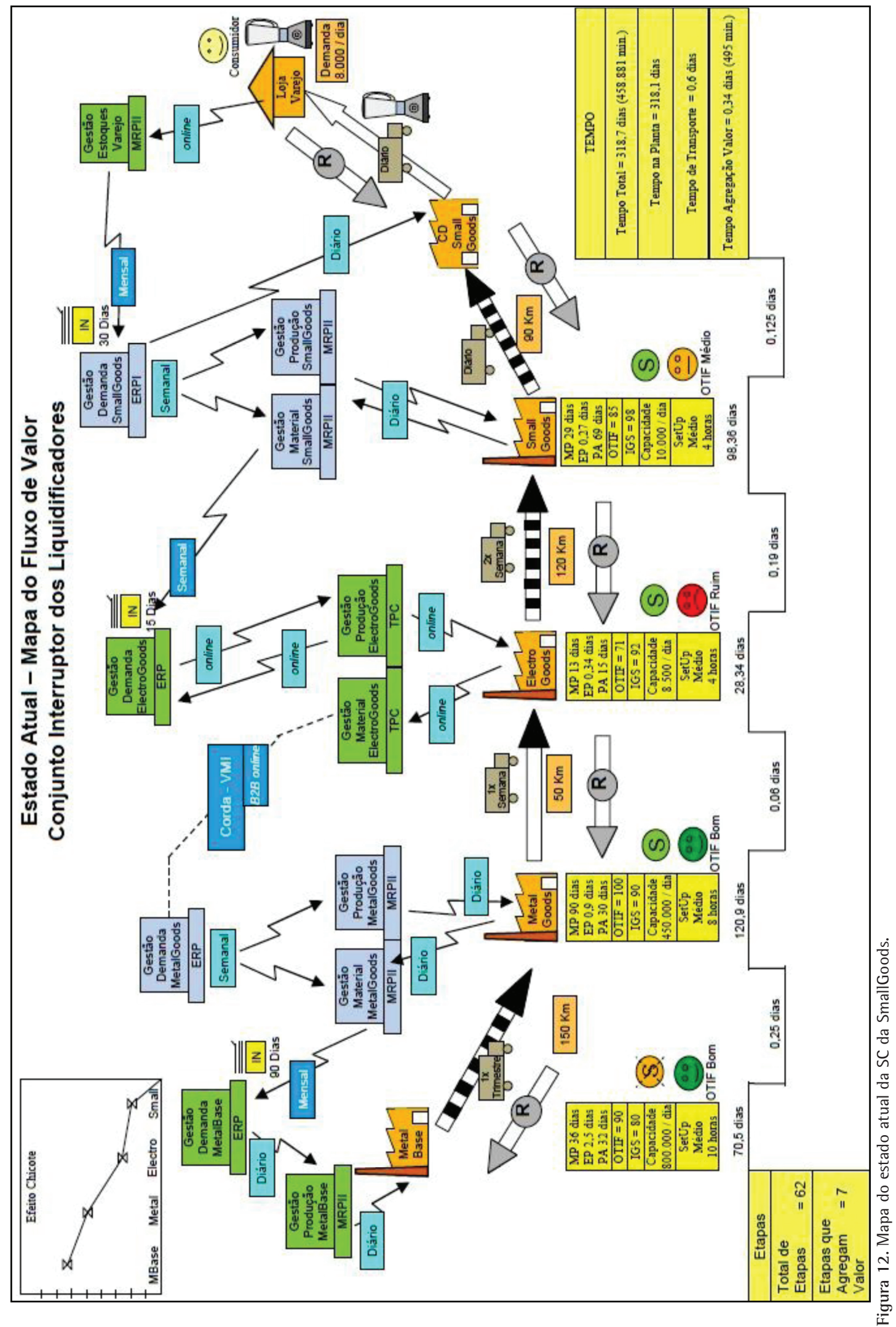


140 PRO

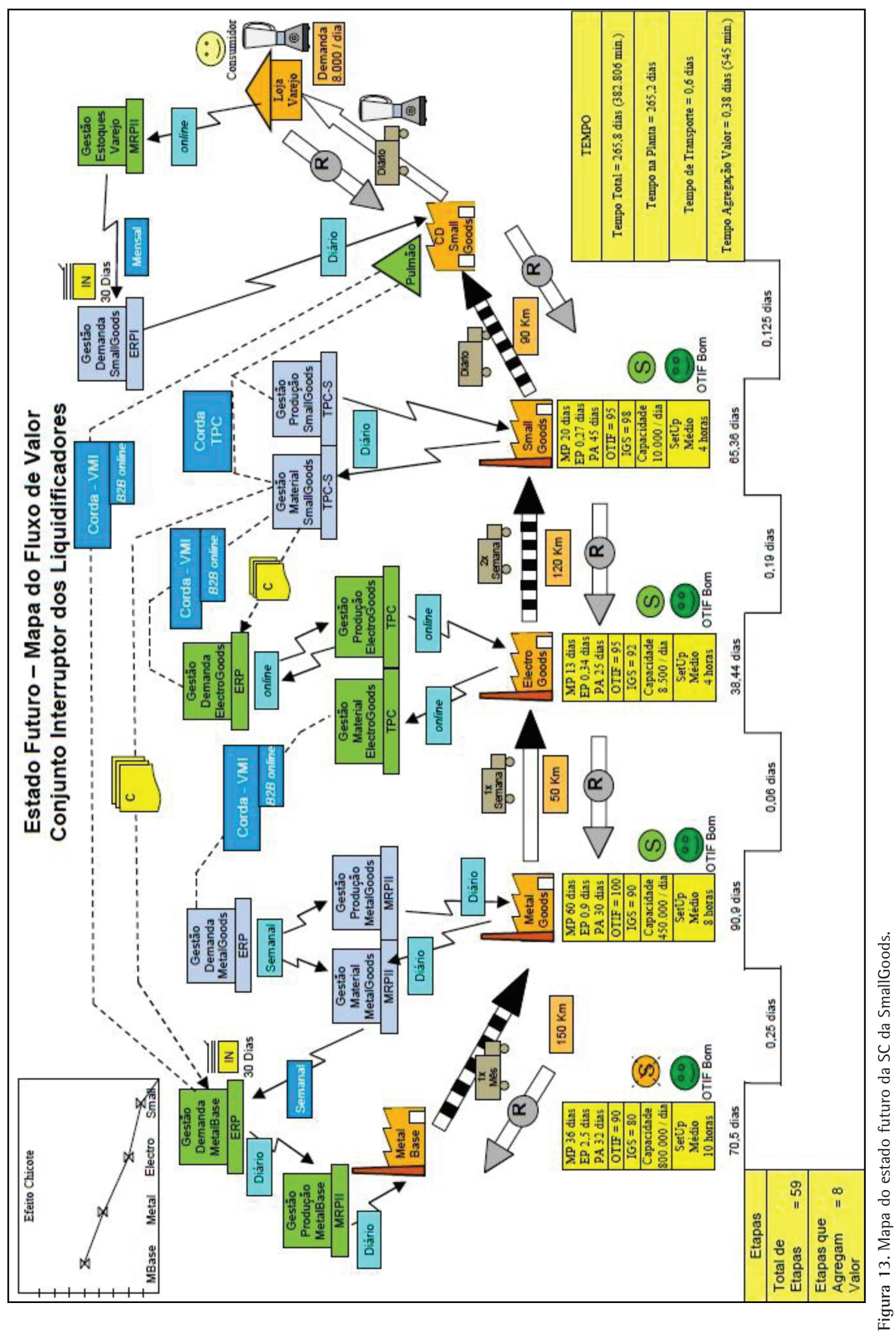


Ao término deste trabalho, grande parte da implantação já havia ocorrido e grande parte dos problemas políticos contornados.

\section{Passo 19: Análise dos resultados obtidos}

Os resultados obtidos, com início e implantação em julho/2010 e análise desses dados em outubro/2010, foram representativos, como mostra a Tabela 3.

Passo 20: Voltar ao passo 1 e não deixar a inércia se tornar uma restrição no sistema

A equipe já se encontra preparada para dar continuidade aos trabalhos, sem a necessidade da participação do pesquisador.

\section{Conclusões}

Operando em um ambiente globalizado e competitivo, as empresas manufatureiras têm tido dificuldades para implementar um modelo de SCM capaz de suprir suas necessidades de forma a garantir o desenvolvimento de vantagens competitivas sustentáveis.

A aplicação do modelo proposto na cadeia de suprimentos da empresa SmallGoods resultou em geração de vantagem competitiva para as empresas estudadas. Mesmo com pouco tempo de implementação, os resultados foram positivos com relação aos três indicadores de desempenho analisados, tanto com relação ao indicador de sustentabilidade, como em relação à redução dos estoques, com significativa redução do efeito chicote, de quase $10 \%$. Mesmo com a redução dos estoques, o principal indicador, pois dele deriva a responsividade ao cliente, o OTIF melhorou em mais de 5\% com relação à média da cadeia. Uma maior integração da cadeia de suprimentos estudada foi comprovada através da redução dos estoques associados à melhoria do nível de serviços ao cliente.

A aplicação também demonstrou o alinhamento dos resultados com o movimento Triple Bottom Line, garantindo prosperidade econômica e aumento da vantagem competitiva para as empresas estudadas, aliada à busca de preservação ambiental e respeito às pessoas. A redução dos estoques evidencia, além das certificações ligadas à sustentabilidade, a contribuição para a obtenção de um planeta mais sustentável. 0 conjunto de indicadores demonstra um maior respeito ao consumidor final, que terá acesso a produtos com preços mais justos, com melhor qualidade e com entregas mais rápidas.

0 modelo proposto procurou maximizar as vantagens de cada um dos sistemas estudados e ao mesmo tempo minimizar as limitações apresentadas por eles e, dessa forma, apresenta ferramentas de simples utilização, que atendem às necessidades dos gestores na busca do sucesso para suas empresas.

\section{Referências}

Ballou, R. H. (2006). The evolution and future of logistics and supply chain management. Produção, 16(3), 375-386. http://dx.doi.org/10.1590/S0103-65132006000300002

Bandeira, R. A. M., \& Maçada, A. C. G. (2008). Tecnologia da informação na gestão da cadeia de suprimentos: o caso da indústria gases. Produção, 18(2), 287-301.

Catalisa. (2010). O Conceito de Sustentabilidade e Desenvolvimento Sustentável. Retrieved from http:// www.catalisa.org.br/site/index.php?option =com content\&view $=$ article $\& i d=30 \&$ ltemid $=59$.

Coelho, L. C., Follmann, N., \& Rodriguez, C. M. T. (2009). 0 impacto do compartilhamento de informações na redução do efeito chicote na cadeia de suprimentos. Gestão \& Produção, 16(4), 571-583. http://dx.doi. org/10.1590/S0104-530X2009000400007

Cooper, M. C., Lambert, D. M., \& Pagh, J. D. (1998) Supply Chain Management: Implementation lssues and Research Opportunities. International Journal of Logistics Management, 9(2), 1-19. http://dx.doi. org/10.1108/09574099810805807

Disney, S. M., \& Towill, D. R. (2003). The effect of vendor managed inventory (VMI) dynamics on the Bullwhip Effect in supply chain. International Journal of Production Economics, 85, 199-215. http://dx.doi. org/10.1016/S0925-5273(03)00110-5

Fioriolli, J. C., \& Fogliatto, F. S. (2009). Modelagem do Efeito Chicote em ambientes com demanda e lead time estocásticos mediante uma nova política de tratamento dos excessos de estoque. Produção, 19(1), 27-40.

Hirschheimer, F. S. (2009). A Integração e o Uso do Sistema Puxado no Planejamento das Cadeias de Suprimentos. In Anais do Simpósio de Administração da Produção, Logística e Operações Internacionais, São Paulo. 15 p.

Hudson, S. (2004). The SCOR Model for Supply Chain Strategic Decisions. Supply-Chain Council. Retrieved from http://scm.ncsu.edu/public/facts/facts041027.html.

Greef, A. C., \& Freitas, M. C. D. (2012). Fluxo enxuto de informação: um novo conceito. Perspectivas em Ciência da Informação, 17(1), 37-55.

Kleindorfer, P. R., Singhal, K., \& Wassenhove, L. N. V. (2005). Sustainable Operations Management. Production and Operations Management, 14(4), 482-492.

Lages, R. T. S., Lages, R. T. S., \& França, S. L. B. (2010) Indicadores de Desempenho com o Conceito do Triple Bottom Line e Metodologia do Balanced Scorecard. In Anais do Congresso Nacional de Excelência em Gestão, Niterói. $18 \mathrm{p}$.

Lambert, D. M. (2010). Customer Relationship Management as a Business Process. Journal of Business \& Industrial Management, 25(1), 4-17. http://dx.doi. org/10.1108/08858621011009119

Low, C., Chen, Y., \& Wu, M. (2011). Understanding the determinants of cloud computing adoption. Industrial Management \& Data Systems, 111(7), 1006-1023. http:// dx.doi.org/10.1108/02635571111161262

Martins, F. C. (2011). Gestão da Cadeia de Suprimentos: Aprimoramento da Metodologia de Diagnostico e Proposição de um Método para Implantação baseado em Processos de Negócio. In Anais do Congresso de Iniciação Científica UNIMEP, Piracicaba. 5 p.

Melo, D. C., \& Alcântara, R. L. C. (2011). A gestão da demanda em cadeia de suprimentos: uma abordagem além da 
previsão de vendas. Gestão \& Produção, 18(4), 809-824. http://dx.doi.org/10.1590/S0104-530X2011000400009

Miguel, P. A. C. (2007). Estudo de caso na engenharia de produção: estruturação e recomendações para sua condução. Produção, 17(1), 216-229. http://dx.doi. org/10.1590/S0103-65132007000100015

Miguel, P. A. C., Fleury, A., Mello, C. H. P., Nakano, D. N., Turrioni, J. B., Ho, L. L., Morabito, R., Martins, R. A., \& Pureza, V. (2010). Metodologia de Pesquisa em Engenharia de Produção e Gestão de Operações. Rio de Janeiro: Elsevier.

Oliveira, A. L. P., \& Silveira, M. A. P. (2010). ERP in the Production Area: User's Opinions about Needs Being Met. Journal of Information Systems and Technology Management, 7(3), 517-544. http://dx.doi.org/10.4301/ S1807-17752010000300002

Oliveira, L. R., Medeiros, R. M., Terra, P. B., \& Quelhas, O. L. G. (2012). Sustentabilidade: da evolução dos conceitos à implementação como estratégia nas organizações. Produção, 22(1), 70-82. http://dx.doi.org/10.1590/ S0103-65132011005000062

Pedroso, M. C., \& Swicker, R. (2007). Sustentabilidade na Cadeia Reversa de Suprimentos: um Estudo de Caso do Projeto Plasma. Revista de Administração USP, 42(4), 414-430.

Perales, W. J. S., Lima, G. M., \& Mitzcun, G. B. (2008). Aplicação do VMl à um Modelo de Gestão Integrada de Estoques em um Órgão Público. In Anais do Encontro Nacional de Engenharia de Produção, Rio de Janeiro.

Pereira, C. R., Melo, D. C., Costa, M. A. B., \& Alcântara, R. L. C. (2010). A Gestão da Demanda em uma Cadeia de Suprimentos Emergente: o Caso de um Frigorífico de Peixe do Estado de São Paulo. In Anais do Encontro Nacional de Engenharia de Produção, São Carlos.

Pereira, P. L. P., \& Cruz, M. M. C. (2007). A SA-8000 como Ferramenta de Gestão da Responsabilidade Social Empresarial. In Anais do Encontro Nacional de Engenharia de Produção, Foz do lguaçu. 11 p.

Pergher, 1., Rodrigues, L. H., \& Lacerda, D. P. (2011). Discussão teórica sobre o conceito de perdas do Sistema Toyota de Produção: inserindo a lógica do ganho da Teoria das Restrições. Gestão \& Produção, 18(4), 673-686. http:// dx.doi.org/10.1590/S0104-530X2011000400001
Pires, S. R. 1. (2009). Gestão da cadeia de Suprimentos (Supply Chain Management): Conceitos, Estratégias, Práticas e Casos. São Paulo: Atlas.

Santos, A. C., \& Forcellini, F. A. (2012). As relações do projeto de produtos com a cadeia de suprimentos: um estudo de caso no setor de eletrodomésticos. Produção, 22(3), 534548.

Santos, R. F. (2010). Proposta de um Modelo de Gestão Integrada da Cadeia de Suprimentos: Aplicação no Segmento de Eletrodomésticos (Tese de doutorado). Instituto Tecnológico de Aeronáutica, São José dos Campos.

Santos, R. S., Marins, F. A. S., Alves, J. M., \& Moellmann, A. H. (2010). A Real Application of Theory of Constraints to Supply Chain Management in Brazil. Brazilian Journal of Operations \& Production Management, 7(2).

Sellitto, M. A., \& Mendes, L. W. (2006). Avaliação comparativa do desempenho de três cadeias de suprimentos em manufatura. Produção, 16(3), 552-568. http://dx.doi. org/10.1590/S0103-65132006000300015

Scor 9.0. (2009). Supply-Chain Operations Reference-Model. Supply-Chain Council. Retrieved from http://www. supply-chain.org.

Souza, F. B. (2005). Do OPT à Teoria das Restrições: avanços e mitos. Produção, 15(2), 184-197.

Srinivasan, M. M., Srinivasan, T., \& Choi, E. W. (2005). Build and Manage a Lean Supply Chain. Industrial Management, 47(5), 20-25.

Stéen, J. (2006). Improving Supply Chain Management with Advanced Planning and Scheduling: Effects and possibilities with an international perspective (Master's thesis). Linköping Institute of Technology, Linköping. 90 p.

Taylor, D. A. (2005). Logística na Cadeia de Suprimentos. São Paulo: Pearson Education do Brasil.

Walter, 0. M. F. C., \& Zvirtes, L. (2008). Implantação da Produção Enxuta em uma Empresa de Compressores de Ar. In Anais do Encontro Nacional de Engenharia de Produção, Rio de Janeiro.

Womack, J. P., \& Jones, D. T. (2004). Enxergando o Todo: mapeando o fluxo de valor estendido. São Paulo: Lean Institute Brasil.

\section{Proposal of an integrated management model for supply chain: application in home appliances segment}

\section{Abstract}

The competitiveness among manufacturing organizations in an increasingly global economy is no longer limited to the competition among organizations, although such competition can occur between supply chains. However, the current models of supply chain management (SCM) are not fulfilling their role, and there is great disparity between potential benefits and practice. The goal of this paper is to propose a model for SCM and its implementation method to increase responsiveness to consumer market manufacturing companies. The proposed model uses the concepts of lean manufacturing, the theory of constraints and the SCOR model in an information and communication technology environment. The triple bottom line concept is also applied to promote sustainability. An evaluation of the model's effectiveness is performed by applying it to the home appliances segment and supports the expansion of its future applicability.

\section{Keywords}

Supply Chain Management (SCM). Theory of Constraints (TOC). Lean Manufacturing (lean). Supply-Chain Operations Reference (SCOR). Information and Communication Technology (ICT). 